\title{
OITENTA ANOS DE GEOPOLÍTICA NO BRASIL: DA GEOGRAFIA MILITAR A UM PENSAMENTO ESTRATÉGICO NACIONAL ${ }^{1}$
}

\author{
Quatre-vingts ans de géopolitique au Brésil: de la géographie militaire à une pensée stratégique \\ nationale $^{1}$
}

Wanderley Messias da Costa

Prof. Titular no Depto. de Geografia na USP

wander@usp.br

Hervé Théry

Pesquisador do CNRS-Creda, Prof. Visitante no Depto. de Geografia na USP

hthery@aol.com

Traduzido em 23/10/2016 e autorizado para publicação em 08/12/2016

DOI: $10.12957 /$ tamoios.2016.

Evocar a Geopolítica brasileira faz inevitavelmente pensar - nos meios interessados no tema - nos generais da época da ditadura militar (1964-1985) que, na verdade, se apoiaram muito em argumentos geopolíticos para justificar suas políticas internas e externas. Sem negar o uso muito ideológico da Geopolítica durante este período, devemos, no entanto, colocá-la em perspectiva — os militares deixaram o poder há quase trinta anos - e ter em conta as mudanças no Brasil, que se tornou atualmente um dos grandes "países emergentes", para ver ao mesmo tempo como evoluiu o pensamento geopolítico brasileiro e como a mudança de status do país se reflete - ou não - na visão que os brasileiros têm do mundo que os cerca e o lugar que eles ocupam nesse mundo.

Analisaremos, assim, em primeiro lugar, a nova Geopolítica brasileira, que se "civilizou" gradualmente, no sentido próprio do termo, à medida que passava das mãos dos militares para a dos civis, dando atenção especial a dois conjuntos estratégicos para o Brasil, a América do Sul e a Amazônia. Por este prisma e em função da nova situação do Brasil na divisão internacional do trabalho, poderemos então tentar medir o fluxo de relações que daí emanam, ou são conduzidas (analisando suas ligações aéreas e seu comércio exterior), de modo a tentar compreender como o mundo é visto do Brasil e qual é atualmente o seu lugar no mundo.

\section{Uma nova Geopolítica brasileira}

A evolução do pensamento geopolítico brasileiro e de sua influência direta ou indireta nas questões que chamamos de estratégicas para o desenvolvimento do Brasil desde as primeiras décadas do século passado (soberania nacional, integridade e coesão territoriais, integração das populações indígenas, independência energética) pode ser resumida em três características principais. Em primeiro lugar, como já foi observado no estudo de Costa (1991), a Geopolítica no Brasil foi durante sessenta anos - de 1920 a 1980 - uma atividade quase exclusivamente reservada aos meios militares do aparelho de Estado. Ela refletia, então, em grande parte, a hegemonia do pensamento autoritário e político do Estado e inspirava as políticas de organização interna do território, as políticas territoriais (ocupação da Amazônia, distribuição da população, redução dos desequilíbrios e tensões entre as regiões) e a projeção externa do poder nacional (satelização dos países vizinhos mais fracos, rivalidade com os mais poderosos, sobretudo a Argentina). 
Em segundo lugar, como aconteceu na Alemanha sob os nazistas e em alguns países da América do Sul, particularmente no Brasil, Chile e Argentina, a Geopolítica foi monopolizada pelo exército ${ }^{2}$. Esta apropriação foi facilitada pelo fato de que se tratava de formular um pensamento e de definir os meios que seriam aplicados às políticas públicas em contextos em que os protagonistas eram muitas vezes ao mesmo tempo quem pensava, decidia e executava essas políticas. A Geopolítica era então instrumental, pragmática e sistematicamente aplicada, seja através da influência dominante do exército na política pública, seja pelos regimes militares que dominaram quase todos os países da região durante os anos 1960 e 1970.

Estes regimes autoritários, além de uma forte centralização do poder político nacional em geral, também foram submetidos ao pensamento e à ação das forças armadas na maior parte das políticas públicas, em particular na sua vertente territorial. Além dos programas regionais de planejamento e de infraestrutura de transportes, por exemplo, também assumiram os programas de colonização de regiões remotas como a Amazônia, a Patagônia e o deserto de Atacama. Eles também exerceram uma forte influência sobre a política externa em seus respectivos países, como reivindicações de soberania sobre a Antártica, Argentina e Chile, e ações conjuntas visando a repressão transfronteiriça de movimentos de resistência a esses regimes. Da mesma forma, as características francamente militares do programa nuclear brasileiro na década de 1970 e o ataque repentino das Malvinas por tropas argentinas em 1982 são ilustrativos da hegemonia da geopolítica militar na região durante este período.

A aplicação prolongada desta abordagem geopolítica pragmática a um país de dimensões continentais como o Brasil permitiu ao Estado, durante os anos sessenta, inspirar e liderar o planejamento estratégico visando a reconfiguração do território. Em outros termos, a ocupação efetiva de áreas de fronteira, as políticas de "integração nacional", os programas de colonização, a ocupação da Amazônia, a construção de Brasília, o planejamento urbano e regional, a alocação de investimentos em infraestrutura de transportes e energia. Em suma, tratava-se de uma implementação autoritária de conceitos e práticas da geopolítica clássica inspirada em Ratzel e Mackinder, e que podem ser resumidos como uma forma radical do princípio da coerência territorial, por uma ocupação o mais homogénea possível do espaço nacional e sua grade por vias de comunicação conectando todas as partes a uma capital apropriadamente localizada.

Os analistas que estudaram a evolução da Geopolítica brasileira concordam em afirmar que o autor que melhor reflete a combinação do pensamento e da prática do que poderíamos chamar a fase de hegemonia militar é Mario Travassos, um oficial que, em 1931, publicou a obra que se tornou a principal referência para a reflexão geopolítica brasileira clássica, Projeção Continental do Brasil. Com ele se desenha pela primeira vez a estratégia que foi aplicada nas décadas seguintes nas políticas brasileiras para a América do Sul. Nesta mesma trajetória deve ser realçada a importância de dois outros militares, ambos inspirados por Travassos, os generais Golbery (Geopolítica do Brasil, 1952) e Meira Mattos (Brasil, Geopolítica e destino, 1975).

O ponto comum entre estes três "generais geopolíticos" é a ideia de que o Brasil deve, por todos os meios à sua disposição, procurar expandir sua influência sobre os países vizinhos da América do Sul, em função do que eles acreditavam ser uma forma de supremacia do país na região. Tratava-se de uma dupla estratégia já delineada por Travassos. Por um lado, o estreitamento das relações económicas e políticas, principalmente com o Uruguai, Paraguai, Bolívia e Peru, para contrapor a influência da Argentina, que era então claramente o rival geopolítico do Brasil. Por outro lado, era a promoção da "integração territorial" entre as duas maiores bacias hidrográficas do Brasil 
(Amazônia e da Prata) e as façadas do Atlântico e do Pacífico. Para isso, como exposto por Golbery, era necessário ocupar e povoar as zonas fronteiriças para promover a

\section{MAPA 1: VISÕES GEOPOLITICAS DAS POLITICAS REGIONAIS}

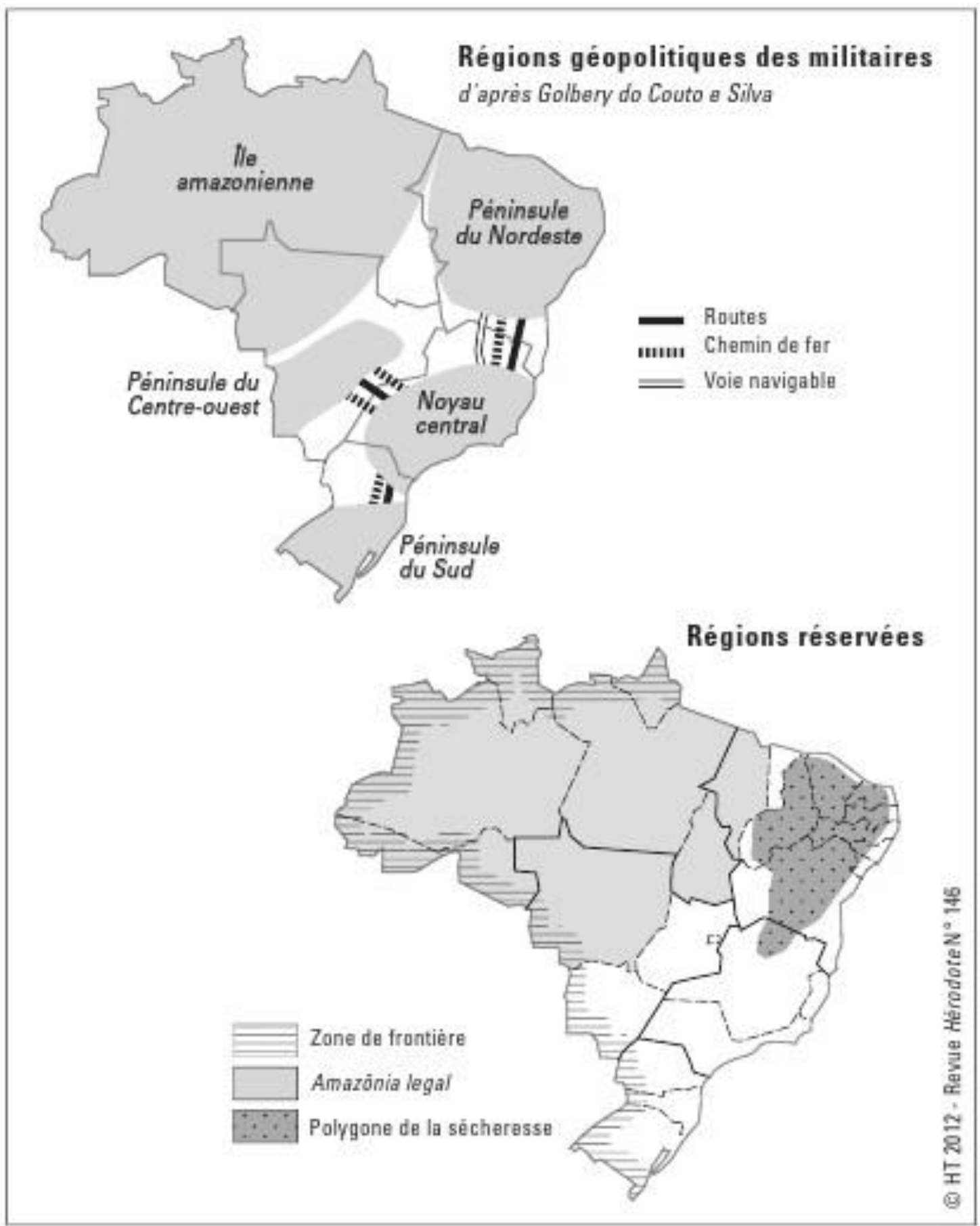

A concepção geopolítica de uma necessária articulação das diferentes partes do país pelos eixos de transporte encontra sua contraparte nas zonas de planificação estabelecidas sob o regime militar.

O desafio - a satelização de toda a Amazônia, além das fronteiras do Brasil - e o meio de obtê-la - a construção de estradas transamazônicas — são anunciadas já na capa do livro. 
ocupação do Planalto Central do país (iniciada com o projeto de criação de Brasília) e, a partir daí, integrar a Amazônia e povoar as fronteiras do Norte. Finalmente, como preconizava Meira Mattos, buscar a cooperação com outros países amazônicos e promover o que chamava de "Pan-Amazônia", uma ideia que seria realizada mais tarde com a criação do Tratado de Cooperação Amazônica. Um ponto suplementar a se observar é que o general Travassos ainda é considerado como um dos inspiradores do exército brasileiro, que Golbery foi um dos criadores da Escola Superior de Guerra, um dos arquitetos do golpe de Estado militar em 1964 e o criador e primeiro diretor do SNI (Serviço Nacional de Informação), o principal órgão da política do regime militar. Meira Mattos, por sua vez, é considerado um dos mais eminentes intelectuais militares do país e ensinou durante décadas na Escola do Comando do Estado Maior do Exército.

Portanto, o desenvolvimento da Geopolítica ocorreu no Brasil, como nos países do que era então chamado Terceiro Mundo, fora do ambiente universitário e intelectual, e devemos reconhecer que este processo de alienação de Geografia e outras ciências não foi unicamente devido à ação deliberada dos meios militares. A comunidade de geógrafos brasileiros, como muitos de seus colegas europeus e norte-americanos, preferiu manter uma "distância segura" da Geopolítica e do que ela considerava como desvios éticos, morais e científicos desta disciplina, em razão de suas aventuras e desventuras durante a Segunda Guerra Mundial. Tratava-se, de fato, de um comportamento típico de exclusão mútua, e a ruptura deste paradigma só se produziu na década de 1980 e refletiu as profundas mudanças que tinham ocorrido em diversas esferas da vida nacional.

Em primeiro lugar, observamos a aceleração do processo de transformação do país, especialmente a industrialização, urbanização e modernização em geral, que tiveram seu ritmo máximo em 1960 e 1970. Ao mesmo tempo, profundas mudanças ocorreram na dinâmica das populações, na estrutura social, especialmente no processo de democratização do país, que se intensificou com a lei de anistia para os presos políticos, exilados e privados de seus direitos em 1969, o direito de livre organização dos partidos, as eleições diretas para governadores em 1982, a Assembleia Constituinte em 1988 e a primeira eleição direta para a presidência em 1989.

É neste novo contexto que surgiram nas universidades os primeiros grupos de intelectuais que se dedicaram ao estudo da Geopolítica como um pensamento explicitamente civil, não-autoritário e relativamente autônomo do Estado. Bons exemplos deste período de transição são as obras de Miyamoto (1981), Becker (1982), Vessentini (1986), Mello (1987) e Costa (1988). O estudo mais emblemático deste período, curto e intenso, de produção acadêmica onde floresce uma nova geopolítica é o texto de Becker "A Geografia e o Resgate da Geopolítica" em 1988. Ele explica a ruptura entre o velho e o novo pensamento neste domínio e indica as pistas para uma reflexão teórica que implica não somente na expansão e diversificação do objeto e dos temas de estudo, mas sobretudo nas abordagens teóricas que permitem reconciliar a Geopolítica com as práticas da Geografia Humana contemporânea e das Ciências Políticas.

Ao mesmo tempo, devemos mencionar o forte impacto no mundo acadêmico brasileiro, da efervescência intelectual francesa causada pelas ideias de Yves Lacoste e sua equipe da Universidade de Vincennes, especialmente entre aqueles que se interessam na relação entre a Geografia, a ideologia e política. A publicação de seu discurso, " $L a$ géographie, ça sert, d'abord, à faire la guerre" (A Geografia serve, em primeiro lugar, para fazer a guerra) (1976), e a edição do primeiro número da revista Heródoto, em 1976, representou uma etapa importante não apenas para a evolução da Geopolítica, mas também e mais geralmente para a da Geografia no Brasil.

A influência francesa nesta renovação da Geopolítica brasileira pode igualmente ser creditada ao trabalho de Raffestin (1980), que, aplicando as ideias de Foucault, oferece a 
primeira análise crítica completa da Geopolítica clássica nascida com Ratzel e mostra também que o poder político e sua organização territorial não se produzem apenas na órbita do estado. Esta inovação teórica e metodológica também pode ser encontrada nas contribuições de Beatrice Giblin (1986), quando ela chama a atenção para as regiões políticas e geopolíticas.

A partir de meados dos anos 1980, este ambiente marcado por uma combinação de modernização e democratização do país como um todo e, particularmente, das instituições, muito favoreceu a emergência de centros de pesquisa e de debate sobre questões direta ou indiretamente geopolíticas e estratégicas. Estes centros, que nos Estados Unidos são chamados de think-tanks, são essencialmente dedicados ao pensamento estratégico que, em geral, reúnem tomadores de decisão, tanto militares como civis, intelectuais, universitários e representantes da sociedade civil em geral. Ao mesmo tempo, multiplicaram-se os doutorados de Terceiros Ciclo em Geografia e Ciências Políticas no campo das Relações Internacionais. Consequentemente apareceu uma forte atividade de pesquisa e reflexão sobre a Geopolítica em praticamente todas os domínios que envolvem direta ou indiretamente os temas da estratégia, do desenvolvimento e política internacional.

Não há dúvida de que, entre as mudanças institucionais deste período, a mais notável é a que ocorreu no coração do pensamento e da gestão política-militar-estratégica do Estado, com a supressão dos ministérios militares (Ministérios do Exército, da Marinha e da Aeronáutica) no início dos anos 2000 e a criação do Ministério da Defesa, que teve um forte impacto sobre o equilíbrio do poder político em nível nacional, mudança analisada pelo excelente estudo de Oliveira (2005). Como os eventos subsequentes plenamente comprovaram, essa mudança na configuração institucional das questões de segurança e de defesa nacionais não pode ser reduzida a uma simples reorganização burocrática. Ela expressa na verdade uma nova maneira de conceber, formular e implementar a estratégia nacional neste domínio e, portanto, influenciou profundamente o curso da Geopolítica no Brasil.

Além disso, o que aconteceu no Brasil reflete uma tendência geral na região, relacionada com a passagem do poder político dos regimes militares para governos democráticos. Em meados dos anos 2000, todos os países sul-americanos haviam estabelecido seus ministérios de defesa e, portanto, subordinado totalmente a segurança nacional e a defesa ao poder civil. No Brasil, isso significou uma grande abertura destas questões nos meios universitários e, em particular, a sua participação nos think-tanks, a que nos referíamos, cada vez mais ativos.

A experiência que melhor simbolizou essa mudança foi o processo de elaboração da política de defesa nacional, adotada em 2005. Pela primeira vez participaram deste tipo de atividade intelectuais de diversos horizontes e orientações ideológicas e políticas, militares e diplomatas, esses últimos desempenhando um papel cada vez mais importante na formulação de políticas relativas à defesa nacional e às estratégias de projeção externa. Outra novidade neste cenário é a interação entre centros de reflexão militares e acadêmicos, o que se traduziu pelo número crescente de oficiais inscritos nos Programas de Pós-graduação das universidades e, por outro lado, no interesse crescente da universidade por essas questões. Sem dúvida a melhor ilustração dessa tendência é a criação e o rápido sucesso da ABED (Associação Brasileira de Estudos de Defesa), local representativo destes "novos tempos" em que as questões de segurança e defesa despertam mais interesse na sociedade civil.

Como consequência deste novo quadro institucional e intelectual, a Geopolítica que se desenvolve no país ampliou significativamente o âmbito e a abordagem de suas reflexões. 
Tomemos, por exemplo, dois objetos de estudo estimados pelos especialistas tradicionais da região, a América do Sul e a Amazônia.

\section{$\underline{\text { A América do Sul e a Amazônia }}$}

\section{A escolha da cooperação}

Para os pensadores militares da época do regime militar (1964-1985), a América do Sul era uma região destinada a ser absorvida pelo transbordamento natural da influência do Brasil. Desde os anos 1980, no entanto, e particularmente ao longo dos últimos quinze anos, os conceitos e as políticas brasileiras para a América do Sul passaram de um de um quadro estratégico claramente focado no exercício da hegemonia e da concorrência com os países vizinhos (principalmente a Argentina) para outro com base nos conceitos e práticas de cooperação regional. Em suma, uma profunda mudança que expressa a passagem de situações de conflitos potenciais e rivalidades à situação atual, em que predomina um franco processo de integração nos domínios da economia, da política, da infraestrutura, da segurança e da defesa.

Esta tendência progressiva em aprofundar a integração sul-americana começou na década de 1980 com os tratados bilaterais entre o Brasil e a Argentina, o que levou à criação do Mercosul na década seguinte. Sob o governo de Fernando Henrique Cardoso (1995-2002), o edifício regional foi consolidado, no campo econômico, pelo crescimento do comércio regional e, no campo político, pela rejeição da proposta dos Estados Unidos de criar a ALCA (Área de Livre Comércio das Américas). Sob o governo Lula (20032010) este processo foi acelerado principalmente em razão dos esforços do Brasil e da Argentina para institucionalizar e expandir o processo de integração, entre os quais os mais importantes foram a entrada da Venezuela (que fez com que o Mercosul articulasse, pela primeira vez, o continente, dos países do Prata aos da Bacia Amazônica), a criação da UNASUL (União das Nações Sul-americanas, de 2008) e do Conselho de Defesa Sulamericana (2008). Além disso, durante este último período, o governo brasileiro investiu maciçamente em um processo de integração económica com base no intercâmbio de investimentos diretos em diversos setores industriais e de infraestrutura e, mais recentemente, serviços especializados. Com isso, a integração sul-americana excede em muito os objetivos iniciais que inspiraram a criação de um bloco de comércio regional e este processo inspirou muitos estudos nos últimos anos.

Uma das obras mais emblemáticas deste processo de mudança na região, e que expressou a crescente simbiose entre os círculos militares e civis em torno das questões estratégicas e geopolíticas, é o livro organizado por Oliveira (2008), intitulado "Segurança e defesa da América do Sul: da competição à cooperação". Num plano mais estritamente geopolítico, alguns estudos igualmente tentaram expressar o tema da integração regional, entre os quais dois foram publicados na França: "Les politiques territoriales brésiliennes dans le contexte de l'intégration sud-américaine" (Costa, 2002) e "O Brasil e a América do Sul: cenários e os desafios da integração" (Costa, 2008). Cabe ressaltar igualmente o livro "Integrações na América do Sul", organizado por Girault (2010) a partir de um seminário organizado por ele no programa Arcus no Instituto de Altos Estudos da USP (Universidade São Paulo), cujos artigos são especificamente dedicados a este tema, notadamente um artigo de Costa e Thery (2010) em que os autores examinam o recente processo de integração regional e identificam quais são, para eles, as forças de convergência e divergência neste cenário. No primeiro caso, são as políticas eficazes de integração econômica, política e estratégica, já mencionadas, que se expressaram concretamente no aprofundamento da cooperação bilateral e multilateral em 


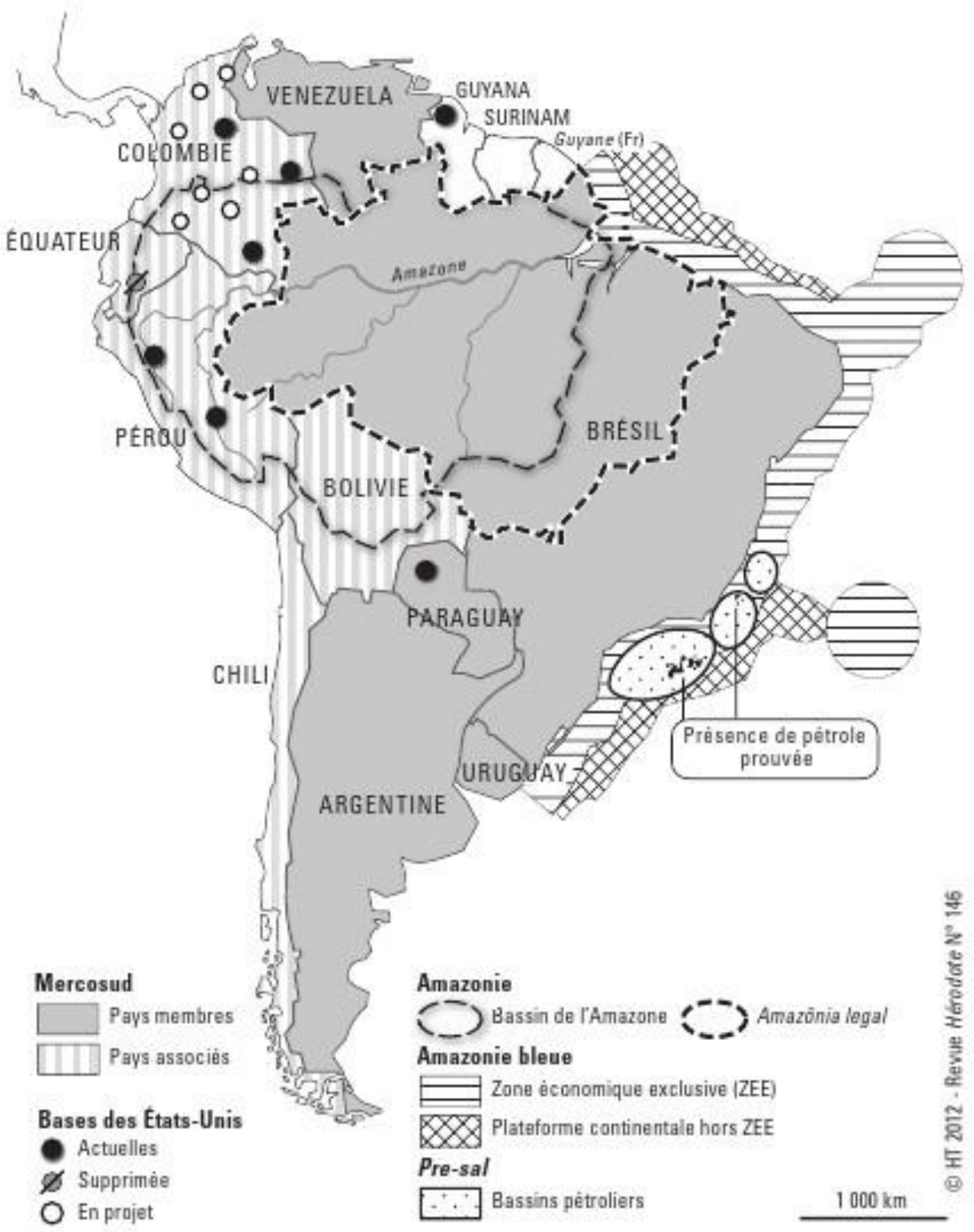

todas os domínios de relações de vizinhança. São evidenciadas, por exemplo, na proliferação de experiências de cooperação transfronteiriça, incluindo aquelas que levam à cooperação no domínio do planejamento urbano, ou aos emblemáticos projetos de infraestrutura de conexão entre os países sul-americanos, por implantação ou reformas de estradas, ferrovias, oleodutos e gasodutos.

Outros estudos examinaram essas mudanças recentes em muitas áreas, tais como os de Guimarães (2008), Ruckert (2008) e Saint-Pierre (2009), abordando notadamente as consequências do aprofundamento de arranjos institucionais multilaterais existentes e a maneira como a região procura se organizar para enfrentar os novos desafios do sistema internacional. No domínio da política regional na América do Sul foi destacado o papel 
da Unasul e do papel desempenhado pelo Brasil e Argentina no processo de resolução do conflito entre Colômbia e Equador (e em parte Venezuela) causada pelo ataque do exército colombiano ao acampamento das FARC no Equador. Também pode ser mencionado o comportamento diplomático e não beligerante do governo brasileiro durante o episódio da nacionalização de instalações da Petrobras na Bolívia. Finalmente, observa-se o claro compromisso do Brasil e Argentina, a fim de minimizar as tensões entre Colômbia e Venezuela causadas pela militarização na Colômbia durante a última década, recentemente agravada pelo fortalecimento do aparelhamento logístico do exército norte-americano no seu território. A ação da Unasul, combinada com a nova posição do governo colombiano atual (que, ao contrário de seu antecessor, é claramente multilateralista, ou seja, engajado com os sistemas regionais de cooperação e disposto a manter o diálogo com os seus vizinhos, em particular com o governo da Venezuela), contribuiu para uma redução significativa das tensões na política regional. Por outro lado, os estudos indicam que, apesar de todos estes esforços de natureza francamente cooperativa, ainda persistem numerosos exemplos da ação de forças divergentes e rivalidades regionais. É o caso, entre outros, dos conflitos fronteiriços agravados pelos tráfegos de todos os tipos, em especial o tráfico de drogas. Disputas fiscais e aduaneiras levaram à criação de obstáculos ao comércio de certos produtos e outros conflitos surgiram a partir do aumento dos fluxos migratórios, frequentemente de brasileiros que se estabeleceram há várias décadas no Paraguai e, mais recentemente, na Bolívia, Peru, Venezuela e Guiana Francesa. Os mais críticos atualmente são os relacionados à presença de pequenos produtores de grãos no Paraguai (os "brasiguaios") e grandes produtores de soja na região oriental da Bolívia (região de Santa Cruz).

Há, no entanto, um consenso entre os especialistas de que o fator de risco mais importante para o futuro da integração é o aprofundamento das assimetrias graves entre os países da região. Se, no início desse processo, já era evidente a desproporção entre as economias, por exemplo, do Brasil, Uruguai e Paraguai, o crescimento do PIB (Produto Interno Bruto) brasileiro, que se acelerou ainda mais na última década, a situação do Mercosul é susceptível de se tornar insustentável se não for adoptada uma política específica visando promover uma maior equidade no desenvolvimento regional, como foi a recente criação dos fundos estruturais, uma prática bem estabelecida na União Europeia e adoptada aqui com o nome de FOCEM (Fundos de Convergência Estrutural e de Fortalecimento Institucional do Mercosul).

Também no domínio dos riscos para a integração, devemos mencionar a persistência dos fatores de tensões de natureza especificamente estratégico-militar. Além de casos de baixa gravidade, como, por exemplo, as disputas de fronteira entre Peru e Equador, Venezuela e Guiana, Peru e Chile, ou a perda - traumática para ela - do acesso a o mar pela Bolívia, o que pode ser considerada uma situação de alto risco é a presença e a recente expansão dos sistemas militares dos Estados Unidos em território colombiano, comprometidos sob o pretexto de apoiar o país em sua luta contra o tráfico drogas ("Plano Colômbia"), mas que na verdade representam um avanço da superpotência na região. É notório que as novas bases militares dos Estados Unidos abrigam aeronaves capazes de voar por mais de seis mil quilômetros, o que significa claramente que o teatro de possíveis operações militares não se limita a áreas dominadas pelo tráfico de drogas colombiano e as FARC. É, portanto, o principal "ponto quente" da América do Sul, a situação mais grave de atrito estratégico e geopolítico, e o tema prioritário de organismos multilaterais e de consulta mútua na região. 


\section{A Amazônia: "vulnerabilidade” estratégica nacional}

Tomando igualmente a política de defesa nacional brasileira (PDN) como referência, é interessante notar quais são as duas prioridades estratégicas para o país. A primeiro é a América do Sul e o papel do Brasil no processo de integração regional. A segunda prioridade é a Amazônia, descrita como a maior "vulnerabilidade" estratégica nacional. Esta região foi um dos principais objetos de preocupação e de pesquisa durante os oitenta anos de reflexão geopolítica brasileira e, de fato, com mais de cinco milhões de quilômetros quadrados, a maior bacia hidrográfica do mundo, abrigando uma das maiores biodiversidades tropicais do planeta, e mais de oito mil quilômetros de fronteiras, mereceria ser considerada como estratégica por qualquer Estado da comunidade internacional.

No apogeu do regime militar, a geopolítica nesta região se materializou essencialmente pelo Plano de Integração Nacional de 1971, que tratava em especial sobre os investimentos em infraestrutura de circulação, produção de energia e telecomunicações, bem como a criação de "polos de desenvolvimento", com base na indústria, na agroindústria e programas de colonização dirigida. Esta estratégia de ocupação, principalmente destinada à defesa da soberania nacional, que cristalizava as visões da antiga geopolítica militar, foi fortemente criticada pela nova geopolítica que se desenvolveu no país a partir dos anos 1980. É o caso da obra de Becker "Geopolítica da Amazônia" (1982), que aponta claramente as tensões entre, por um lado, os imperativos da defesa da soberania nacional pela ocupação e integração a todo custo, e, por outro, as consequências deste modelo de planejamento territorial autoritário e centralizado, entre os quais pode-se citar os conflitos fundiários relacionados à expansão agrícola, desapropriação e a violência exercida contra populações tradicionais, especialmente comunidades indígenas, e danos ao meio ambiente, sobretudo o desmatamento acelerado.

O que poderia ser chamada de uma segunda fase dos estudos da Amazônia numa perspectiva geopolítica foi em grande parte inspirada pela formidável influência do debate internacional sobre o futuro da região em termos de sustentabilidade ambiental, durante a conferência do Rio em 1992, e seus efeitos sobre a produção acadêmica e as políticas territoriais, especialmente sobre o meio ambiente. Devemos também mencionar o programa de zoneamento ecológico-econômico da Amazônia, que gerou pesquisas aprofundadas sobre os aspectos físicos, bióticos e socioeconômicos da região, além de apoiar políticas visando o ordenamento do território e do meio-ambiente nos nove estados da Amazônia. Outros estudos procuraram explorar a transversalidade das questões ambientais nas políticas para o território amazônico, para demonstrar que é um caminho árduo, mas também o mais adequado para abordar este domínio na perspectiva que inspira a nova geopolítica brasileira. O trabalho que melhor expressa esta tendência é o de Neli Aparecida de Mello-Théry, "Território e gestão ambiental na Amazônia" (2011).

Também nesta perspectiva, podemos citar a iniciativa do Centro de Gestão para Estudos Estratégicos (um think-tank na órbita do governo), que aprofundou os estudos engajados no Plano por uma Amazônia Sustentável, de onde nasceu o livro "Um projeto para a Amazônia do século XXI", que se visa resumir o que seria um projeto de desenvolvimento sustentável para a região, governado pelos princípios de proteção e melhoria dos direitos sociais, culturais e ambientais. Trata-se de um esforço conceitual e analítico que procura manter o imperativo da soberania brasileira sobre este território, integrando os desafios de sua gestão descentralizada, participativa e fundada na cooperação internacional (CGEE, 2009).

Enfim, deve-se notar que os últimos anos viram a consolidação de um novo sujeito geopolítico, a costa, as águas territoriais brasileiras e do Atlântico Sul. Trata-se de um 
novo tema estratégico para o país, desenvolvido a partir de meados da década de 1990 com a aplicação dos princípios definidos pela Convenção das Nações Unidas sobre os direitos do mar, o que permitiu ao país definir uma zona económica exclusiva de 200 milhas. Ao mesmo tempo, a expansão da exploração petrolífera no mar permitiu a descoberta de depósitos de petróleo na camada chamada de Pré-Sal, alguns dos quais localizados dentro dos limites de águas brasileiras. Assim, o país se abre a um novo desafio estratégico que concerne agora o potencial de influência para além da ZEE, a área ampliada da plataforma continental (às vezes chamado de "Amazônia Azul") e do Atlântico Sul. Os textos mais recentes sobre o assunto são, por exemplo, "Prospectiva, estratégias e cenários globais - visões do Atlântico Sul, da África lusófona, da América do Sul e da Amazônia" (IPEA, 2011), que salienta que o desafio é precisamente a capacidade do país, nos próximos anos, para combinar habilmente duas políticas. Por um lado, uma ação especificamente militar-estratégica visando defender a soberania estendida do país e a expansão da influência do país nesta região. Por outro lado, avançar no Atlântico Sul para reforçar os laços de cooperação com os países ribeirinhos, sulamericanos e africanos, com base nos princípios que inspiram sua política externa como um todo. Em outros termos, ser guiado pela defesa da paz e pela manutenção dessa parte do Atlântico como uma zona livre de armas nucleares, pela franca cooperação internacional e pela defesa e proteção da integridade dos recursos naturais marinhos.

Finalmente, os especialistas chamam a atenção para o fato de que a expansão das áreas sob sua soberania e o aumento das zonas de influência do país, especialmente para as águas profundas do oceano, representam um ambiente estratégico novo e difícil e que, portanto, o país deveria estar preparado para fazer investimentos significativos na modernização a curto e médio prazo das suas forças armadas, em particular o reequipamento da Marinha. Daí a importância da do programa de modernização da frota brasileira, em particular o acordo estratégico entre o Brasil e a França, em 2008, que inclui a construção de cinco novos submarinos, um deles movido a energia nuclear, que deveria ser lançado em 2020.

Face a estes novos desafios, decorrentes da nova posição do Brasil na divisão internacional do trabalho e do poder, como evolui a imagem que os brasileiros fazem do mundo e do lugar que nele ocupam?

\section{O mundo visto do Brasil}

A visão que o Brasil tem do mundo ainda não está bem definida. Mesmo a opinião mais informada não é muito consciente das grandes mudanças da posição do país no cenário mundial. Longe de considerar o país como uma potência mundial - o que provavelmente está em vias de se tornar - ou pelo menos como uma potência emergente - que já é amplamente - ela ainda muitas vezes o "complexo de vira-latas", uma frase cunhada pelo escritor e dramaturgo brasileiro Nelson Rodrigues, que se referia originalmente ao trauma sofrido pelos brasileiros em 1950, quando a seleção brasileira foi batida pela equipe uruguaia na final da Copa do Mundo no Maracanã. Como essa imagem pode evoluir? Será interessante observar nos próximos anos, à medida que se firmar a nova posição do país.

Ainda é preciso se interessar pelo resto do mundo. Ora, o Brasil é um país essencialmente autocentrado, a grande maioria dos brasileiros têm pouco interesse no resto do mundo, no que se passa "lá fora" (no exterior). Isso é compreensível se pensarmos que a maioria deles nunca viajou para o exterior e que os habitantes dos dois principais núcleos de povoamento do país estão a quase 2.000 quilômetros da fronteira mais próxima (para grandes cidades do Sudeste, como São Paulo e Rio de Janeiro), ou 
mais de $4.000 \mathrm{~km}$ (para as do Nordeste, Recife e Fortaleza). A imprensa quase não ajuda, fala pouco do exterior e muito raramente compara o Brasil com outros países, exceto para dizer que ele é o maior ou o melhor, ou às vezes o pior do mundo (complexo de vira-latas ...). Podemos acreditar numa maior abertura quando vemos a mesma mídia informar regularmente os resultados de campeonatos de futebol dos principais países europeus, mas logo percebemos que apenas de times onde atuam jogadores ou treinadores brasileiros ...

Isso não significa que o Brasil não esteja preocupado com a globalização, ao contrário, ele faz isso profundamente - na verdade, é o faz desde a chegada das caravelas portuguesas - com seu comércio exterior, sua dívida, sua integração cultural. Isso não significa que sua diplomacia não seja ativa, nem que sua expansão não tenha consequências sobre seus vizinhos, alguns dos quais falam às vezes de "imperialismo brasileiro", como no tempo da ditadura militar, sem que isso os impeça de consumir seus produtos, de vir ao Brasil de férias ou para estudar. Para avaliar objetivamente o lugar do Brasil no mundo, escolhemos duas áreas, os fluxos aéreos e comércio internacional, o fluxo de pessoas e mercadorias que revelam as orientações das suas relações privilegiadas com alguns países.

\section{Fluxos aéreos}

Quatro empresas brasileiras têm redes internacionais, cujo projeto enfatiza regiões do mundo com as quais o Brasil mantém intercâmbios mais intensos. Todas privilegiam nitidamente três direções, países vizinhos da América do Sul, Europa e Estados Unidos. Em períodos mais prósperos, a Varig tinha linhas para o Japão, através da Califórnia, para Bangkok, via África do Sul, e para Angola e Nigéria, mas esses tempos de glória terminaram e o pragmatismo levou as empresas brasileiras a se concentrarem nas rotas mais rentáveis.

Felizmente, muitas companhias aéreas estrangeiras operam no Brasil, oriundas de países com os quais tem laços de longa data (vizinhos da América do Sul, Estados Unidos, Japão e Europa), mas também daqueles com quem suas relações se desenvolveram mais recentemente, notadamente a China, os Emirados Árabes Unidos e Turquia. Esta última opera para o Senegal, o que atenua um pouco o vazio africano, já que as ligações com o esse continente ocupam um lugar-chave na diplomacia brasileira, que se resume a uma linha para Angola e outra para a África do Sul, ambas realizadas por empresas estrangeiras.

\section{Comércio exterior}

O comércio exterior do Brasil mostra bem as orientações de seus intercâmbios, sua evolução recente e o lugar do país no mundo de hoje. Os principais parceiros são os vizinhos do Mercosul (principalmente a Argentina), os Estados Unidos, a Europa, e cada vez mais a China, cujo peso era muito limitado há dez anos. Ela hoje ultrapassou muito o Japão como o principal parceiro asiático, através de suas compras maciças de minério de ferro, soja, carne e açúcar, em troca de uma variedade de bens manufaturados, dos mais banais (têxteis de baixa qualidade) aos mais sofisticados (eletrodomésticos e informática).

O saldo ainda é positivo para o Brasil, assim como com a Rússia, com vários países do Oriente Médio (tendo o Brasil adquirido sua autossuficiência em petróleo em 2006) e com os seus vizinhos da América do Sul, com exceção da Bolívia, de quem compra gás sem pode lhe vender muito em troca, em razão de sua pequena população e, ainda mais, do seu baixo poder de compra. Em oposição, os saldos são negativos com os Estados 
Unidos e a Europa, que vendem ao Brasil produtos de alto valor unitário e compram principalmente minérios e produtos agrícolas, com a notável exceção de aeronaves da Embraer.

O Brasil tem, portanto, uma posição muito específica na divisão internacional do trabalho. Para a fabricação de produtos tecnológicos, tem um saldo positivo com os países menos desenvolvidos que ele na América do Sul, África e Oriente Médio, e saldos negativos com as grandes potências económicas. Isso significa que ele ocupa uma posição intermediária entre os países desenvolvidos do "centro" (dos quais compra produtos manufaturados e serviços e vende produtos primários), e os países mais "periféricos" que ele (vizinhos da América do Sul, os produtores de petróleo da África e do Oriente Médio), aos quais vende bens manufaturados e compra produtos primários, o que reflete sua posição intermediária entre "Sul" e "Norte".

Esta posição foi também revelada nas ações desenvolvidas no âmbito da OMC, a Organização Mundial do Comércio, uma contra a proteção concedida pelos Estados Unidos a seus produtores de algodão, a outra contra a proteção concedida pela União Europeia aos seus produtores de açúcar, e ganhou as duas (o responsável pelo caso também queria atacar o Japão sobre sua proteção do mercado nacional de arroz, e ainda hoje se lamenta ter sido dissuadido por seu chefe). Nem tudo está resolvido, os Estados Unidos arrastam os pés, procrastinam, mesmo sob a ameaça de represálias contra seus produtos sensíveis, mas em ambos os casos o Brasil espera ganhar quotas de mercado, suas vantagens comparativas lhe permitindo produzir mais e mais barato do que os seus concorrentes. Este retorno ao status quase-colonial de produtor de bens brutos e comprador de produtos manufaturados é o perigo temido por alguns, e que tem um nome, o comoditizaçâo, o risco de ver o Brasil retroagira alguns séculos, ao status de produtor de commodities, matérias-primas que outros países garantiriam a transformação. Isto é obviamente inaceitável para um país que já está bem engajado no caminho do desenvolvimento industrial e cuja economia já é baseada principalmente em serviços. E isso pesa naturalmente sobre a visão que o Brasil tem o mundo.

\section{Que lugar no mundo?}

As relações com os vizinhos da América do Sul já foram analisadas acima. A África (e mais amplamente os países de língua portuguesa) e os outros grandes países emergentes (os chamados BRIC, Brasil, Rússia, Índia e China) foram objeto de cuidados do governo Luiz Inácio Lula da Silva ao longo seus dois mandatos (2003-2006 e 2007-2010). Lula fez dez viagens à África, em 25 dos 53 países do continente durante estes oito anos. Por exemplo, em outubro de 2007, durante sua sétima viagem, ele foi acompanhado por empresários dos setores de energia, construção, indústria aeronáutica e finanças, e fez paradas em Burkina Faso, na República do Congo, na África do Sul e Angola. A agenda incluía a assinatura de acordos bilaterais e multilaterais e participação na segunda cimeira do Fórum de Diálogo Índia-Brasil-África do Sul (IBAS). Isto era coerente com a sua política de abertura para o sul, e com a vontade de retomar o legado de Portugal em Angola, Moçambique e Guiné-Bissau. Os resultados de todas essas viagens foram, contudo, decepcionantes e vozes dissidentes observaram que por querer se colocar demais na África - cujo PIB é de apenas $1 \%$ do planeta - o Brasil estava perdendo participação de mercado em países que importantes para ele, na América do Norte, Europa e Ásia.

A China está hoje na mira do Brasil, a cada trimestre os observadores comparam a progressão do PIB nacional ao daquele país, e a opinião teme que o Brasil fique para trás: a principal manchete da Folha de S. Paulo de 26 de agosto de 2011, que tratava sobre o crescimento do PIB para 2011 foi imediatamente seguida da frase: "Se a projeção do 
governo se confirmar, o Brasil vai crescer menos do que outros países, como a China e a Índia, mas a um ritmo mais rápido do que o de países desenvolvidos, como os Estados Unidos. Sua economia está sofrendo a concorrência chinesa em muitos setores, como o têxtil, que já perdeu mais de 250.000 postos de trabalho na última década".

As esperanças dos primeiros anos do governo Lula, que havia retornado de sua primeira viagem à China encantado com as perspectivas de cooperação foram, portanto, decepcionantes, como já havia acontecido com tantos chefes de Estado antes dele nas mesmas circunstâncias. Sua eleição em janeiro de 2003, havia marcado um ponto de viragem nas grandes orientações da diplomacia brasileira; desde 2003, o discurso tornouse significativamente de Terceiro Mundo, especialmente sob a liderança do número dois do Ministério das Relações Exteriores, Samuel Pinheiro Guimarães Neto, e iniciativas tinham sido tomadas para direcionar a diplomacia brasileira para o Sul, e jogando com países emergentes.

O Brasil pode realmente jogar em ambos os sentidos e é o que ele está constantemente tentando fazer, concentrando-se tanto em um quanto no outro. Ele tenta maximizar suas vantagens, principalmente como grande produtor de produtos agrícolas e biocombustíveis, minimizar suas fragilidades, sobretudo sua dependência tecnológica e financeira, e estimular dinâmicas de recomposição de posições em relação a outros países, desenvolvidos de um lado, os países pobres de outro, valendo-se de sua situação intermediária.

Um episódio mostra bem a ambiguidade da situação, a nacionalização dos hidrocarbonetos na Bolívia, que foi mal vivenciada pela opinião pública brasileira. A principal exploradora era a Petrobras, e o quase confisco de suas refinarias foi visto como um atentado ao prestígio, ou mesmo à soberania do país. O governo do Partido dos Trabalhadores (PT) e a opinião esclarecida estavam estupefatos de se encontrar no papel de potência imperialista, acusada de saquear os recursos naturais de um país pobre, enquanto que aqui se considerava o país como uma vítima desse mesmo jogo face aos países desenvolvidos do Norte.

Assim, a reação foi constrangedora, o governo inicialmente deu razão à Bolívia, até que as considerações económicas vieram à tona. A demissão do ministro boliviano de hidrocarbonetos (após ao desmentido da Presidência da sua decisão de fazer da Petrobras uma simples operadora de suas duas refinarias na Bolívia) deu origem à única resposta firme do Brasil, mas no geral a reação foi suave. Tudo indica que esta é apenas a face visível de uma negociação discreta e deveria terminar com um acordo sobre um preço intermediário entre o preço antigo, muito baixo, e o pedido pela Bolívia, muito maior. $\mathrm{O}$ Brasil precisa do gás boliviano enquanto aguarda a exploração do gás descoberto ao largo de Santos, e a Bolívia precisa vender seu gás, antes que a produção do campo de Santos extinga a demanda brasileira. Na verdade, o Brasil está apenas começando a aprender os lados negativos do seu novo peso continental: rebaixado pelos chineses ao rang de produtor de commodities básicas, de preferência a preços baixos, é tratado como potência imperialista pela Bolívia ...

Esta ambivalência também apareceu em reuniões internacionais importantes, onde o Brasil é visto e atua como um líder das reivindicações do Sul (G20, G33 ...). Este foi notavelmente o caso na reunião da OMC em Cancun em 2003, onde contribuiu para bloquear as negociações organizando a resistência dos países do Sul e para impedir um acordo que parecia decidido. Infelizmente, não houve seguimento, nem no naufrágio das negociações de Doha, nem em outros fóruns internacionais ou em iniciativas na luta contra a fome, durante um tempo apoiada por Lula e Jacques Chirac. Os países parceiros observaram - com a polidez requintada dos diplomatas - que o Brasil deveria talvez 


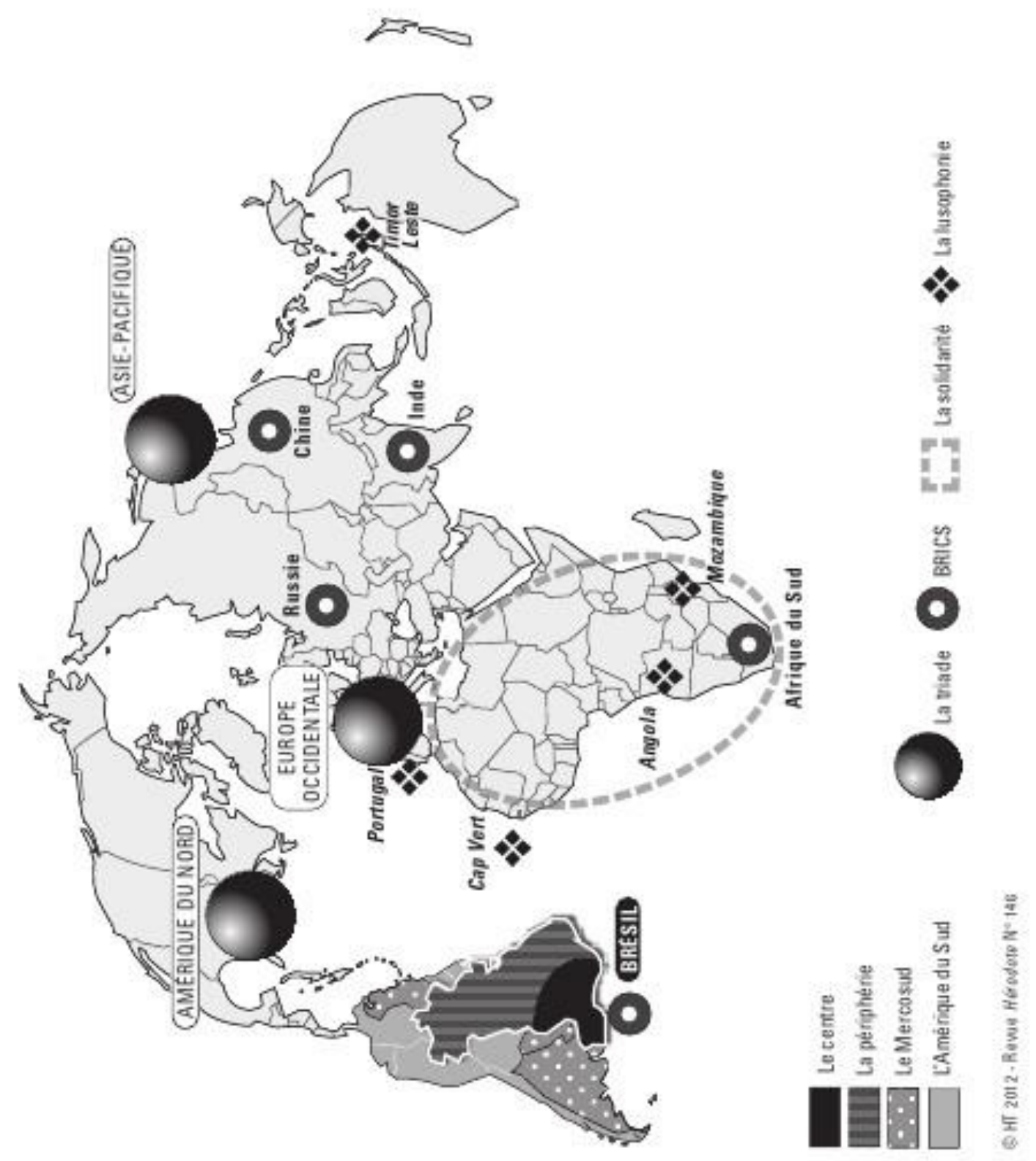

refletir sobre o fracasso de seu programa Fome Zero (incluído sem glória e sem ruído em programas assistência já mencionados) antes de dar lições ao resto do mundo ...

Ao mesmo tempo, o Brasil reivindica, como uma grande potência emergente, um assento permanente no Conselho de Segurança da ONU. Não obteve muito sucesso nessa direção, seus esforços são contrariados pelas ambições e contramanobras de sua vizinha Argentina, ou ainda do México. É pouco provável que isso seja alcançado, o Brasil dificilmente pode ter sucesso onde a Alemanha e o Japão falharam. Os esforços feitos para colocar os brasileiros à frente de grandes organismos internacionais também falharam, em parte por falha em obter o acordo dos seus vizinhos, que também são 
concorrentes. Uma exceção foi a recente eleição do "pai” do programa Fome Zero, José Graziano, para a direção da FAO (Food and Agriculture Organization) em junho de 2011.

Estes contratempos na diplomacia multilateral, apesar do esforço enviando tropas para manter a ordem no Haiti (e, assim, pagar seu bilhete de acesso ao rang dos países que contam nas relações internacionais), ilustram bem a posição ambígua de Brasil, um país emergente, situado ao mesmo tempo no pelotão de frente das principais economias do mundo e um país ainda subdesenvolvido em muitos aspectos. Na verdade, o Brasil ganhou um considerável peso específico por sua população (mais de 190 milhões de habitantes), pela potência de sua agroindústria e de seu aparelhamento industrial, sem equivalente no hemisfério sul, mas ainda não encontrou o seu lugar, quer nas grandes ligas, onde ele pesa pouco, ou como líder dos pequenos, onde os mais pobres o consideram grande demais, e onde outros países emergentes jogam seu próprio jogo. E continua a pensar uma geopolítica que leva em conta a nova posição do Brasil no cenário internacional, a que se dedicam atualmente muitos pesquisadores civis e militares, principalmente aqueles reunidos pela Associação Brasileira de Estudos de Defesa (ABED).

\section{Conclusão}

Em conclusão, constatamos com prazer que, pelo menos em um domínio, sua superioridade não é contestada, o futebol, como testemunham suas cinco vitórias na Copa do Mundo, e mais ainda suas exportações de jogadores para o mundo inteiro. Quase mil deles jogam em clubes de oitenta países do mundo. O país que mais recebeu jogadores é Portugal, por razões linguísticas óbvias. Mas vimos também jogadores partir para o Japão, Coréia e outros para os países mais exóticos para os brasileiros (especialmente porque a maioria dos jogadores é de origem popular e são bem pouco preparados para a vida no estrangeiro): Indonésia, Vietnã, China, Azerbaijão, Finlândia, etc. Note-se que entre 2004 e 2008, enquanto o seu número diminuiu em países vizinhos, como Coreia do Sul e Japão, aumentou rapidamente na África do Sul, nos países do Golfo e, especialmente, na Europa de Leste, países cujo papel internacional se firmou nestes anos. Mesmo nesta área de diversão (mas também, e cada vez mais, um negócio), é claro que a posição do Brasil na globalização se reforçar e pode, então - além de uma saudação - usar o futebol como um símbolo desta afirmação: esporte importado da Grã-Bretanha com os primeiros caminhos de ferro, foi muito transformado: o jogo de cavalheiros inventado em gramados de Eton tornou-se um esporte de massa que levanta o fervor de massas mestiças e coloridas, e os brasileiros, incorporando o seu senso de ritmo e improvisação, muitas vezes dominaram as equipas europeias. Não sem cair em desespero às vezes, quando a Seleção nacional perde uma partida. Realmente, esta não é uma metáfora ruim ... 


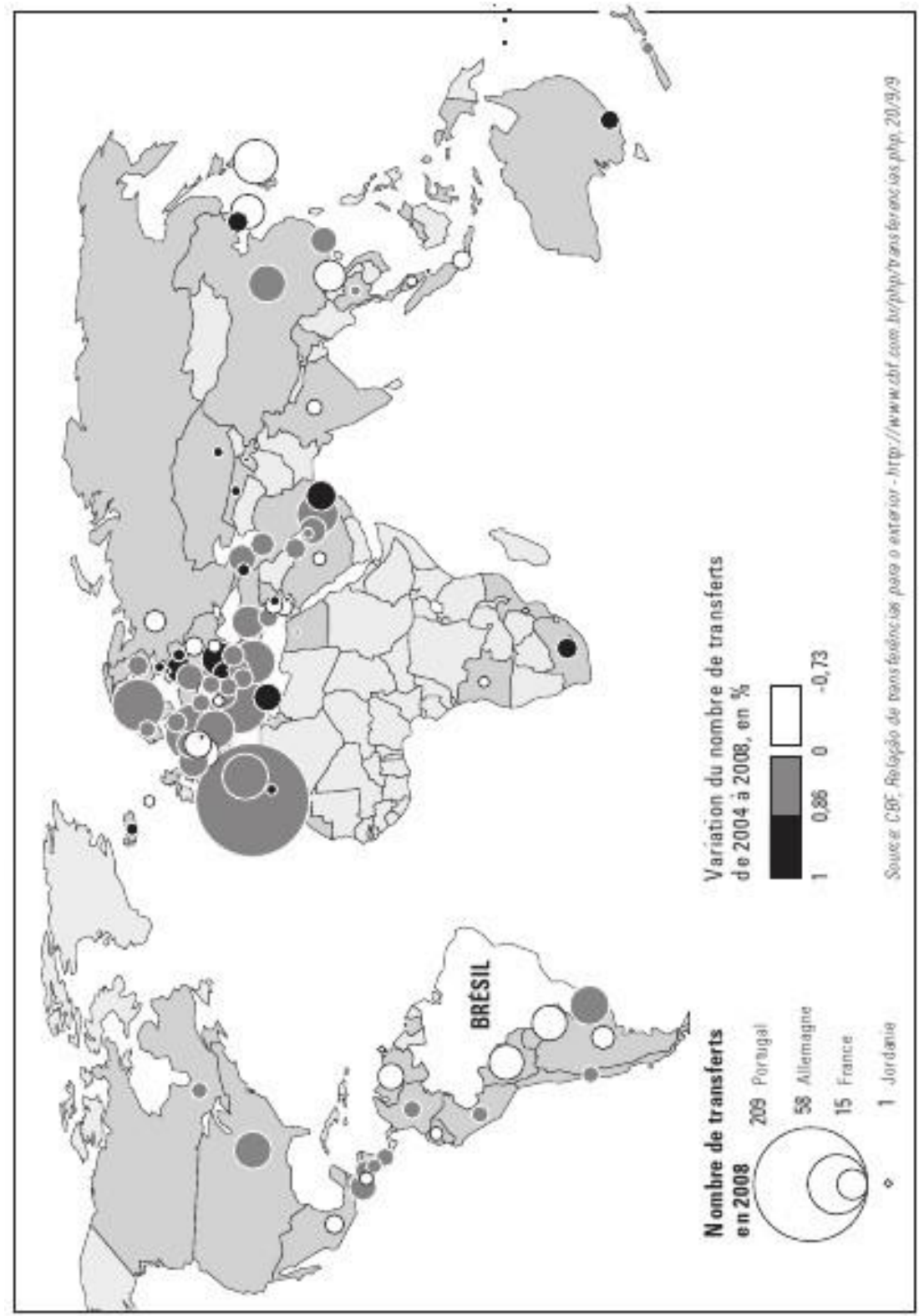

\section{Notas}

1 - Publicado em Hérodote, n⿳0146-147. La découverte, $3^{\mathrm{e}}$ trimestre 2012, p. 253-276 e traduzido pela Professora Adjunta do Departamento de Geografia da FFP-UERJ, Heloisa Helena Gomes Coe.

2 - Observaremos, entretanto, que o exército brasileiro havia contribuído na luta contra a Alemanha nazista durante a Segunda Guerra Mundial, no fronte italiano. Antes do golpe de Estado de 1964 suas intervenções na vida política eram principalmente de esquerda, como o Movimento dos Tenentes, nos anos 1920, e o Capitão Lamarca, que foi um dos líderes da luta armada contra ditadura militar até sua morte, com armas à mão, em 1971. 


\section{$\underline{\text { Bibliografia }}$}

BECKER, B. Geopolítica da Amazônia: A nova fronteira de recursos, Zahar, Rio de Janeiro, 1982.

BECKER, B. A Geografia e o resgate da Geopolítica, IBGE, Revista Brasileira de Geografia, Rio de Janeiro, número especial, 1988.

CGEE. Um projeto para a Amazônia no século 21: desafios e contribuições, DF, Centro de Gestão e Estudos Estratégicos, Brasília, 2009.

COSTA, W. M., THÉRY, H. Les politiques territoriales brésiliennes dans le contexte de l'intégration sud-americaine, in GIRAULT C. Intégrations en Amérique du Sud, Presses Sorbonne nouvelle, Paris, 2010.

COSTA, W. M. da. O Estado e as políticas territoriais no Brasil, Contexto, São Paulo, 1988.

COSTA, W. M. da. Geografia Política e Geopolítica: discursos sobre o território e o poder, HUCITC-EDUSP, São Paulo, 1992.

COSTA, W. M. da. Políticas territoriais brasileiras no contexto da integração SulAmericana, Território, Rio de Janeiro, nº 7, p. 25-41, 1999.

COSTA, W. M. da. Les politiques territoriales brésiliennes dans le contexte de l'intégration sud-américaine, Problèmes d'Amérique Latine, n46-47, automne-hiver, 2002.

COSTA, W. M. da. Brasil e América do Sul, cenários geopolíticos e os desafios da Integração, in OLIVEIRA E. R. (dir.), Segurança \& Defesa na América do Sul: da competição à Cooperação, Fundação Memorial da América do Sul, São Paulo, 2008.

COSTA, W. M. da. Ordenamento territorial e Amazônia, Vinte anos de experiências de zoneamento ecológico-econômico, in BATISTELLA M., MORAN E. e ALVES D. (dir.), Amazônia: natureza e sociedade em transformação, Edusp, São Paulo, p. 241-274, 2008.

COUTO E SILVA, G. Geopolítica do Brasil, Ed. José Olympio, Rio de Janeiro, 1952.

GIBLIN, B. Introduction générale et Géopolitique du Nord-Pas-de-Calais, in LACOSTE Y. (dir.), Géopolitiques des régions françaises, Fayard, Paris, 1986.

GIRAULT, C. Intégrations en Amérique du Sud, Presses Sorbonne nouvelle, Paris, 2010. GUIMARÃES, S. P. O mundo multipolar e a integração sul-americana, Comunicação \& Política, vol. 25, n. 3, p. 169-189, 2008.

IPEA. Prospectiva, estratégias e cenários globais. Visões do Atlântico Sul, África lusófona, América do Sul e Amazônia, 2011.

LACOSTE, Y. La géographie, ça sert, d'abord, à faire la guerre, Maspero, Paris, 1976. MEIRA MATTOS, C. de. Brasil, geopolítica e destino, Editora José Olímpio, Rio de Janeiro, 1975.

MEIRA MATTOS, C. de. Uma Geopolítica Pan-Amazônica, Biblioteca do Exército, 1980.

MELO, L. I. A geopolítica do Brasil e a Bacia do Prata, dissertação (mestrado) - PUCSP, São Paulo, 1987. 
MELLO-THÉRY, N. A. de. Território e gestão ambiental na Amazônia, Annablume, 2011.

MIYAMOTO, S. O Pensamento geopolítico brasileiro: 1920-1980, dissertação (Mestrado em Ciência Política) - Faculdade de Filosofia, Letras e Ciências Humanas, USP, São Paulo, 287 p., 1981.

OLIVEIRA, E. R. Democracia e Defesa Nacional, Editora Manole, Barueri, 2005.

RUCKERT, A. A. Usos do território e políticas territoriais contemporâneas: alguns cenários no Brasil, União Europeia e MERCOSUL, in O.L.C. FIRKOWSKI (dir.), Transformações Territoriais: experiências e desafios, Letra Capital, Rio de Janeiro, p. 17-38, 2010.

SAINT-PIERRE, H. L. La Defensa em la Politica Exterior del Brasil: el Consejo Suramericano y la Estrategia National de Defensa, Analisis del Real Instituto Elcano, v. DT, p. 50, 2009.

THÉRY, H. Le Brésil et le monde, in ROLLAND, D. e LESSA, A.C. (dir.), Les Relations internationales du Brésil, les chemins de la puissance, L'Harmattan, Paris, p. 61$72,2010$.

THÉRY, H. Le Brésil du complexe du vira-lata à la puissance émergente, dossier Les

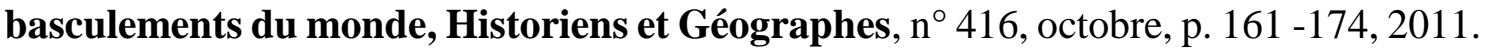

TRAVASSOS, M. Projeção continental do Brasil, Cia. Editora Nacional, Rio de Janeiro, 1931.

VESENTINI, J. W. A capital da geopolítica, Editora Ática, São Paulo, 1986. 